\title{
Percurso profissional dos licenciados em educação física e desporto, com opção de futebol, pela Universidade de Trás-os-Montes e Alto Douro, entre 1992 e 2006
}

\author{
Victor Maçãs \\ Carlos Valadar \\ António Serôdio \\ José Carlos Leitão \\ Jaime Sampaio \\ Nuno Leite
}

\author{
Departamento de Desporto \\ Universidade de Trás-os-Montes e Alto Douro \\ Portugal
}

\section{RESUMO}

O presente estudo teve como objectivo avaliar a inserção profissional dos licenciados em educação física e desporto com opção de futebol, pela Universidade de Trás-os-Montes e Alto Douro. A amostra foi constituída por licenciados $(n=59)$ que frequentaram a especialização em futebol, entre os anos de 1992 a 2006. Na recolha dos dados utilizámos um questionário, adaptado do Observatório do Percurso Profissional da Universidade de Trás-os-Montes e Alto Douro. A análise estatística, essencialmente descritiva, foi realizada através do SPSS Com base nas respostas dos licenciados ao questionário (34\% do universo), verificámos que os licenciados ingressaram na licenciatura por gosto pessoal e devido às boas expectativas de saídas profissionais. A escolha do futebol esteve relacionada com a possibilidade de trabalhar no "mundo do futebol". Os licenciados estão empregados em $96.6 \%$ dos casos, sendo a grande maioria enquanto professores de educação física. No domínio do futebol, $93.2 \%$ dos casos já trabalharam nesta área, mas apenas 3.3\% dos casos o fazem exclusivamente neste sector de actividade. Destacamos as funções de treinadores, coordenadores técnicos e Scout's.

O vínculo contratual mais usual é o contrato a prazo, mas muitos fazem-no em regime de prestação de serviços (recibos verdes). Os valores auferidos situam-se entre os 1000 e 1500 euros, nos empregos principais. Nos empregos complementares, os valores situam-se entre os 250 e 500 euros. A grande maioria revelou não pretender fazer estudos de pósgraduação, mas quase todos frequentaram ou pretendem frequentar cursos especializados no âmbito do futebol. Concluímos que os licenciados têm uma taxa elevada de empregabilidade. No caso dos licenciados com opção de futebol, na generalidade, exercem funções relacionadas com a sua especialização. No entanto, a baixa remuneração não permite o desempenho destas funções a tempo inteiro.

Palavras-chave: inserção profissional, mercado emprego, profissões desporto, emprego, futebol

\begin{abstract}
Professional career of graduates in physical education and sport with specialization on soccer by the University of Trás-os-Montes and Alto Douro, between 1992 and 2006

The present study purpose was to evaluate the professional placement of graduate in physical education (soccer specialization) by University of Trás-os-Montes e Alto Douro. The sample was constituted by graduate students $(n=59)$ from 1992 to 2006. For data gathering we used a questionnaire. The statistic analysis, essentially descriptive, was carried by SPSS.

The answers (34\% of the student population) permitted us to verify that the graduates have chosen this curriculum based on good professional expectations. Soccer specialization choice was related with the possibility to work in "soccer environment".

The graduates are employed in $96.6 \%$ of the cases, being the great majority physical education teachers. In soccer domain in $93,2 \%$ of the cases had already worked in this area, but only 3,3\% do it exclusively. Functions as coaches, technical coordinators and Scout's were detached. The contractual bond in majority is limited in time, but many of them are freelancers. Income is placed among 1000 and 1500 euros in fulltime jobs and, in second jobs between 250 to 500 euros. The great majority does not intend to do postgraduate studies, but almost all have already attend or intend to attend soccer specialized courses. We concluded that graduates have a high job rate and the ones with soccer specialization work in this domain. However, the low income does not allow them to have this activity a fulltime job.
\end{abstract}

Key-words: professional insertion, job market, sports professions, soccer, job 


\section{INTRODUÇÃO}

As saídas profissionais dos alunos do ensino superior são alvo das preocupações de todos os envolvidos neste processo, desde os alunos e respectivas famílias, as instituições de ensino, o mercado de trabalho, os responsáveis políticos e a sociedade em geral. Esta é uma questão cada vez mais actual, tendo como referência os últimos dados estatísticos do desemprego em Portugal, onde os jovens licenciados ocupam um destaque especial.

A inserção profissional pode ser entendida "como um processo segundo o qual um indivíduo ou um grupo de indivíduos que nunca pertenceu à população activa deseja uma posição estabilizada no sistema de emprego". Esta resulta de uma consolidação de vários factores, podendo culminar numa boa ou má integração, tanto no mercado de trabalho, como a nível social(16).

Estudos relacionados com a inserção profissional dos agentes de desporto, quer no domínio da educação física, quer no domínio do desporto, enquanto treinadores, gestores ou outra actividade profissional, não são usuais, tratando-se de um tema pouco aprofundado. No entanto, noutras áreas é frequente existirem estudos desta natureza e estão descritos na literatura $(1,5,9,4,13)$.

Os percursos profissionais dos jovens licenciados podem ser alvo de análise e reflexão profunda, no sentido de compreendermos a receptividade e a integração destes quadros no mercado de trabalho, bem como instrumento de reorientação das competências a desenvolver nos alunos para uma melhor capacidade de resposta às exigências que a vida profissional activa vai colocando. Esta deve ser uma das preocupações dos sistemas de formação e qualificação de recursos humanos, como contributo decisivo para a melhoria do capital humano das organizações da sociedade dos nossos dias.

O ensino superior é actualmente reconhecido como um factor estrutural para o desenvolvimento económico e social, bem como para o reforço da própria competitividade. Nesta perspectiva, vários autores ${ }^{(10}$, 15) afirmam que as entidades empregadoras valorizam uma boa formação de base, condição para o desenvolvimento de capacidades de natureza superior, a disciplina e o rigor do pensamento. A ênfase é assim colocada nas capacidades e competências transversais necessárias à maioria dos novos postos de trabalho. Sabemos que as questões da empregabilidade e da relevância das formações no Ensino Superior ganharam uma nova visibilidade política com a Declaração de Sorbonne ${ }^{1}$ e Declaração de Bolonha ${ }^{2}$. Daí resultou um alinhamento de políticas nacionais com vista à adopção de um quadro comum de referência para os diferentes sistemas de graus académicos, por um lado; e, por outro, a definição de instrumentos que facilitem esse movimento, com vista a promover a empregabilidade e a mobilidade dos cidadãos, bem como melhorar a competitividade internacional do ensino superior europeu(8).

Esta linha de pensamento induziu a várias mudanças na estruturação do ciclo de estudos no ensino superior, que culminaram na adesão ao Tratado de Bolonha, cujos reflexos operacionais estão em execução.

Longe de se conceber que a função da Universidade se reduz à formação profissional e à colocação da "mão de obra" qualificada no mercado de trabalho, de acordo com a sua necessidade, esta não pode ficar indiferente a essa realidade e à real inserção dos seus licenciados no mundo do trabalho(1).

As universidades deverão proporcionar uma boa preparação de base, tendo em vista o encarar de uma grande variedade de situações novas. Não obstante, de acordo com as orientações do Conselho de Reitores das Universidades Portuguesas (2) e do Observatório Permanente para a Qualidade de Ensino(Universidade do Algarve) (14), esta opção não deve ser impeditiva de se desenvolver um ensino vocacional que transmita os conhecimentos necessários para a execução de tarefas específicas de uma dada profissão. O Conselho de Reitores tem vindo a alertar para a necessidade de transformar as universidades em parceiros de entidades públicas, de empresas, de estruturas de desenvolvimento local, regional e nacional(10). É nesta linha de pensamento que são apontadas novas responsabilidades não só em termos de formação e de educação, mas também no que se refere à empregabilidade e à investigação para o desenvolvimento.

$\mathrm{Na}$ educação física e desporto, o desenvolvimento e aplicação da formação tem assinalado um progresso considerável ao nível do ensino superior. Contudo, o facto de estar profundamente associada ao sistema educativo constitui um entrave à criação de uma 
interdisciplinaridade na matriz do desporto, ficando esta condicionada aos conceitos (ou mesmo preconceitos) da "ginástica" e "educação física"(11), ficando assim esquecidas ou desvalorizadas as responsabilidades no domínio do desenvolvimento do desporto. Urge assim a necessidade de cooperação entre o sistema de formação e as entidades responsáveis pelo desporto, permitindo a formação e a integração de quadros técnicos especializados.

No final dos anos oitenta, a Universidade de Trás-osMontes e Alto Douro ampliou as suas ofertas educativas, com a criação ${ }^{3}$ da licenciatura em educação física e desporto, que funcionou a partir do ano lectivo de $1988 / 89$, cujo lema se orientava para (i) levar para a escola o clube; (ii) levar o clube para a escola; (iii) levar para a comunidade, o desporto(7).

No ano lectivo 1990/91, face ao plano curricular da licenciatura, surgiram os percursos formativos de especialização no âmbito das modalidades desportivas, onde naturalmente aparece o futebol. Pelos aspectos sociais, culturais, económicos e impacto mediático desta modalidade, espontaneamente se verificou que os alunos escolheram o futebol como disciplina opcional, na esperança de uma futura inserção profissional no "mundo do futebol". Apesar deste sonho poucas vezes declarado, os alunos ao longo dos anos foram apreendendo que "uma opção pelo futebol pressupõe uma motivação profunda que nos conduz, implica uma paixão intensa (...) mas exige também uma coragem sem fim e uma resistência a todas as adversidades porque o caminho é longo e quase sempre agreste." (3, pp. 60).

Neste contexto, o conhecimento dos percursos sócio-profissionais dos licenciados em educação física e desporto pela Universidade de Trás-os-Montes e
Alto Douro, com especialização em futebol e as respectivas percepções sobre a formação adquirida, revelam-se como um factor importante para justificar a pertinência deste estudo.

Nesta linha definimos os seguintes objectivos:

(i) Avaliar a opinião dos ex-alunos em relação à licenciatura e opção de futebol;

(ii) Avaliar as condições de inserção profissional dos licenciados;

(iii) Caracterizar o percurso profissional dos licenciados em termos de situação contratual, remuneração, tipo de instituição empregadora e função exercida no mercado de trabalho do Futebol;

(iv) Identificar as necessidades de contacto com a instituição de formação inicial, após licenciatura.

\section{MATERIAL E MÉTODOS}

A população do nosso estudo é constituída pelos licenciados em educação física e desporto, com especialização em futebol, pela Universidade de Trás-osMontes e Alto Douro. Este universo representa um conjunto de 174 licenciados.

A amostra utilizada foi constituída por 59 antigos alunos da opção de futebol (os que responderam ao questionário), representando os alunos que concluíram a licenciatura entre 1993 e 2006, correspondendo a $34 \%$ do universo. O Quadro 1 apresenta a caracterização da amostra por ano de licenciatura e sexo. $\mathrm{O}$ instrumento utilizado foi construído com base no questionário utilizado pelo gabinete de saídas profissionais (GASP) da Universidade de Trás-os-Montes e Alto Douro, adaptado aos objectivos do estudo e ao grupo alvo a que se dirigiu. Elaborámos uma primeira versão do questionário que foi aplicada num grupo de 15 indivíduos, licenciados com opção de

Quadro 1. Respostas ao questionário, por ano de licenciatura e sexo

\begin{tabular}{|l|lll|lll|lll|}
\hline \hline \multirow{2}{*}{ Anos de Licenciatura } & \multicolumn{2}{|l|}{ Sexo Feminino } & \multicolumn{2}{l|}{ Sexo Masculino } & \multicolumn{2}{l|}{ Total } \\
& Env & Resp & (\%) & Env & Resp & [\%] & Env & Resp & [\%] \\
\hline $1993-1995$ & 1 & 1 & 100 & 37 & 15 & 40,5 & 38 & 16 & 42,1 \\
$1996-1998$ & - & - & - & 47 & 8 & 17 & 47 & 8 & 17 \\
$1999-2001$ & 4 & 2 & 50 & 42 & 10 & 23,8 & 46 & 12 & 26 \\
$2002-2004$ & - & - & - & 27 & 11 & 40,7 & 27 & 11 & 40,7 \\
$2005-2006$ & - & - & - & 16 & 12 & 75 & 16 & 12 & 75 \\
\hline TOTAL & 5 & 3 & 60 & 169 & 56 & 32,5 & 174 & 59 & 33,9 \\
\hline \hline
\end{tabular}


futebol e 3 professores da universidade com experiência em trabalhos de campo através da utilização destes instrumentos.

A versão final do questionário contempla perguntas de escolha múltipla, perguntas fechadas e uma única pergunta aberta. A estrutura do questionário está organizada em sete tópicos: (i) identificação do licenciado; (ii) questões relacionadas com a licenciatura; (iii) questões relacionadas com a opção de futebol; (iv) questões relacionadas com a situação perante o emprego; (v) questões sobre o percurso profissional; (vi) posicionamento do licenciado perante os estudos de pós-graduação; (vii) questão aberta sobre eventuais observações, comentários ou sugestões. Os questionários foram distribuídos por correio postal e correio electrónico, havendo casos em que o entregámos pessoalmente. A recolha de informação processou-se entre Março e Julho de 2007. A análise exploratória dos dados foi realizada recorrendo à estatística descritiva, através do software SPSS (versão 15.0).

\section{RESULTADOS E DISCUSSÃO}

A apresentação dos resultados segue a estrutura do questionário. Começaremos por apresentar os resultados relativos à opinião dos licenciados sobre a licenciatura e opção de futebol, depois destacaremos os dados sobre a situação perante o emprego e por fim, as necessidades de contacto com a instituição de formação inicial.

\section{Opinião sobre a licenciatura e opção de futebol}

Os factores apontados como decisivos na escolha da licenciatura foram o "gosto pessoal" com 41,5\%, seguindo-se "saídas profissionais" com 21,1\% e "boa componente prática" (13\%). A positividade do primeiro factor poderá revelar uma mais-valia, uma vez que a maioria dos licenciados entraram por gostarem da licenciatura em causa, o que aumenta a sua motivação na frequência do curso. Os outros dois factores revelam uma preocupação mais profunda na escolha do curso, pois reportam-se às expectativas dos licenciados aquando a sua entrada no curso, o que poderá indicar que houve uma pesquisa prévia sobre o curso. Contudo, é de salientar que as respostas obtidas para o factor "Saídas profissionais" foram obtidas, na sua maioria, pelos licenciados mais anti- gos, pelas facilidades encontradas em ingressar no ensino publico, já que os recém-licenciados sentem mais dificuldades, na actualidade, para iniciar a actividade profissional.

A opinião positiva dos licenciados sobre a licenciatura, recaiu nos factores "formação teórica" com uma percentagem de $95 \%$, seguido de "qualidade pedagógica" com 91\%, "qualidade científica" e "formação prática" com percentagens muito próximas de $89 \%$ e $88 \%$, respectivamente. Os factores com opiniões menos favoráveis foram a "divulgação no mercado de trabalho" (46\%) e o "contacto com a realidade exterior" $(35 \%)$.

Em relação à opção de futebol, os factores determinantes na decisão de ingresso, no $3^{\circ}$ ano da Licenciatura, continuou a vigorar o "gosto pessoal" com um valor de $39,4 \%$. O "contacto com mundo do futebol" foi outro dos factores mais respondido $(23,6 \%)$ e a "boa componente prática" com $15,7 \%$. A avaliação dos licenciados em relação aos aspectos positivos e negativos da opção foram as qualidades pedagógicas e científicas (96\%), formação teórica (95\%) e formação prática $(91 \%)$.

Tal como na opinião sobre a licenciatura, os factores apontados como menos favoráveis, foram a "divulgação no mercado de trabalho" e o "contacto com a realidade exterior" com valores de $47 \%$ e $23 \%$. Em função destes resultados, as sugestões apresentadas para aperfeiçoamento da opção, por $40 \%$ dos licenciados, apontaram para uma melhoria do contacto com o mundo do futebol e melhorias nos apoios aos centros de treino, nomeadamente na supervisão do processo de condução das equipas, bem como na possibilidade de existir apoio financeiro ao trabalho desenvolvido. Os licenciados destacam ainda a necessidade de existir um reforço nas competências práticas dos alunos.

\section{Situação perante o emprego}

A situação de emprego dos licenciados inquiridos, relativamente ao Futebol, é bastante clara, dado que $93.2 \%(n=55)$ dos licenciados já trabalharam nesta área e $6.8 \%(\mathrm{n}=4)$ nunca o fizeram após a licenciatura.

Os dados sobre a avaliação do emprego actual dos licenciados, podem ser observados no Quadro 2. 
Quadro 2. Como os licenciados avaliam o seu emprego actual

\begin{tabular}{lllll}
\hline \hline & \multicolumn{2}{l}{ Opinião Negativa } & \multicolumn{2}{c}{ Opinião Positiva } \\
\hline \hline FACTORES & Resp & $(\%)$ & Resp & $(\%)$ \\
\hline Realização pessoal & 9 & 16 & 42 & 75 \\
Salário/remuneração & 25 & 45 & 26 & 46 \\
Adequação da formação às tarefas desempenhadas & 3 & 5 & 48 & 86 \\
Estabilidade do emprego & 26 & 46 & 25 & 45 \\
Perspectivas de progressão na carreira profissional & 27 & 48 & 24 & 43 \\
Perspectivas de melhorias salariais & 32 & 57 & 19 & 34 \\
Actualização de conhecimentos/desenvolvimento profissional & 13 & 23 & 38 & 68 \\
Ambiente sócio-profissional & 6 & 11 & 45 & 80 \\
Localização do emprego & 7 & 13 & 44 & 79 \\
Horário laboral & 4 & 7 & 47 & 84 \\
Prestígio social & 14 & 25 & 37 & 66 \\
\hline \hline
\end{tabular}

Com o intuito de caracterizar o percurso profissional dos licenciados que responderam, passaremos a analisar as profissões e entidades empregadoras, tanto no sector da educação como no mundo do futebol. Antes de passar a qualquer análise do ponto de vista profissional, é importante mencionar que o intervalo do " $1^{\circ}$ emprego" ao " $4^{\circ}$ emprego" é abordado de duas formas diferentes. Os licenciados mais antigos definem um trajecto de profissões, onde houve mudança de entidade empregadora e (principalmente) de emprego; ao passo que os licenciados mais recentes apresentam uma acumulação de empregos que pode chegar a quatro ou mais, juntando os sectores de educação e do futebol.

Com o apoio da literatura, Marques(9) afirma que a configuração de mercados de entrada e de transição, a partir dos licenciados que declaram um ou mais empregos, permite-nos replicar algumas das principais tendências associadas às dificuldades de acesso ao primeiro emprego, ao prolongamento deste período de inserção e ao facto de a estabilização no emprego ser menos rápida no início, mas também no decurso da carreira.

Quanto às denominações dos empregos, nota-se um claro domínio da profissão de "professor de educação física", representando uma elevada procura, tanto no início do processo de inserção profissional, como em processo de consolidação de uma carreira profissional, ao longo dos vários empregos relatados. Estes valores não constituem grande novidade para nós, uma vez se tratar de uma licenciatura via ensino e assim apresenta como principal objectivo a formação de professores de educação física para o $2^{\circ}$ e $3^{\circ}$ ciclos do ensino básico e ensino secundário.

Outras das profissões foram agrupadas como "monitor de actividade física". Considerámos neste âmbito, os licenciados que exercem funções de professor de actividades físicas e/ou desportivas em autarquias (ou através destas), em associações ou em instituições privadas.

Na categoria profissional denominada de "outro", cabem as profissões de vereador do desporto; técnico superior de educação física e desporto; coordenador técnico e pedagógico e professor universitário. No âmbito do futebol verificámos que a maioria dos licenciados na área do futebol, referiram o desempenho da função de "treinador" com percentagens elevadas (64\% a $77 \%$ ), nos diferentes empregos vivenciados. No nosso entender estes dados são bastante positivos, visto que vão de encontro às expectativas e experiências adquiridas na formação alcançada na opção. Todavia, é importante realçar que apenas 2 $(3,3 \%)$ dos 59 inquiridos têm profissões exclusivamente ligadas ao Futebol, os restantes $(96,6 \%)$ acumulam as profissões da área do futebol com as da área da educação física. 
É importante referir ainda, outras denominações de profissões que estes licenciados desempenham, como treinador adjunto, coordenador técnico, jogador profissional; preparador físico; dirigente desportivo e scout's (Observação e análise do jogo).

Quanto às entidades empregadoras mais referenciadas, surge o estado, através do Ministério da Educação. Nos últimos anos, também a administração pública local tem assumido um papel de relevo, no enquadramento dos jovens licenciados, nas actividades de enriquecimento curricular (disciplina de expressão físico-motora) do $1^{\circ}$ ciclo do ensino básico. No futebol, verificámos que a liderança do mercado de emprego está a cargo dos clubes, com valores percentuais de $(73 \%$ a $87 \%)$, desde o $1^{\circ}$ ao $4^{\circ}$ emprego. As outras entidades empregadoras que se destacam como alternativas, são as associações de futebol, as escolas de futebol e até o desporto escolar.

No entanto, é importante referir que os empregos nas associações estão a cargo dos licenciados mais antigos, por cumprirem os normativos legais necessários para serem requisitados ao quadro das escolas. $O$ vínculo contratual que os licenciados mantêm com as entidades empregadoras são na sua maioria, através de "contrato a prazo". Observa-se ainda que muitos licenciados exercem as suas funções em regime de prestação de serviços (recibos verdes), na ordem dos $25 \%$, o que revela um vínculo débil. A remuneração auferida por estes licenciados no emprego principal, em $38 \%$ dos inquiridos situa-se nos valores "De 1000 a menos de 1500 euros". Nos empregos complementares, a maioria dos licenciados respondeu que auferem "de 250 a menos de 500 euros".

Após a análise do questionário, podemos constatar que a maioria dos empregos com remuneração de "menos de 250 euros", estão relacionados com a área do futebol, que surge como uma actividade complementar, mais no âmbito da realização pessoal, do que propriamente os benefícios salariais. Esta leitura deve ser salvaguardada pelo facto de muitos licenciados, especialmente os mais recentes e ainda aqueles que conjugam as profissões de professor e treinador, complementarem as suas remunerações através do exercício de vários empregos. Outro dado que procurámos saber foi o tempo de espera para os licenciados obterem o seu primeiro emprego. De acordo com o Instituto do Emprego e Formação Profissional(6) o tempo de procura de emprego após a licenciatura implica indiscutivelmente um forte envolvimento e actividade dos candidatos. No caso do nosso estudo, dos licenciados inquiridos, 57 (96.6\%) estão empregados e apenas 2 (3.3\%) não exercem nenhuma actividade profissional.

Constatámos ainda que $50 \%$ dos licenciados já tinham emprego mesmo antes de concluírem o curso, devendo referir que estes dados dizem respeito aos licenciados mais antigos. Actualmente o cenário é diferente, havendo mais dificuldade na procura do primeiro emprego, mas os dados apontam para uma boa inserção profissional, havendo casos em que esperam dois a três meses pela colocação (estamos a falar de empregos temporários e sem grandes condições de estabilidade profissional).

O processo de obtenção de emprego mais referido foi através de concurso público (Diário da República / Ministério da Educação). Parece-nos um dado esperado porque se trata de um curso via ensino e como tal uma das saídas naturais é (foi) a escola pública. Por outro lado, os inquiridos referiram que o factor "conhecimentos pessoais" teve uma grande influência na obtenção dos empregos, com valores que variam entre os $27 \%, 41 \%, 44 \%$ e $50 \%$, respectivamente para os $1^{\circ}, 2^{\circ}, 3^{\circ}$ e $4^{\circ}$ empregos. Por estes dados, este factor assume-se como preponderante na inserção profissional dos licenciados do estudo. Reparamos que este factor tem a mesma preponderância noutros cursos, através de outras investigações $(1,5,9)$.

É importante realçar que o factor que ocupa o terceiro lugar no pódio do conhecimento dos empregos é o "contacto directo com os empregadores" com valores de $10 \%$ no $1^{\circ}$ emprego; $22 \%$ no $2^{\circ} ; 25 \%$ no $3^{\circ}$; e $21 \%$ no $4^{\circ}$ emprego. Parece-nos então que os licenciados pela Universidade de Trás-os-Montes e Alto Douro demonstram uma forte auto-iniciativa na procura dos seus empregos.

No que diz respeito aos factores que influenciaram a obtenção de empregos por parte dos licenciados referiram os seguintes factores favoráveis:

Os factores favoráveis destacados pela nossa amostra foram o "grau de licenciatura" como preponderante na obtenção dos seus empregos, auferindo $16,6 \%$ do total das respostas. O facto de ser um "curso específico" $(13,4 \%)$, nomeadamente a opção de futebol, 
teve o seu peso na influência dos empregos dos licenciados, seguido do "bom relacionamento social" com $12,7 \%$.

Relativamente às razões que conduzem à mudança de emprego, houve uma grande variedade de respostas. Dos licenciados que afirmaram ter mudado de emprego, o factor "realização profissional" foi o mais assinalado $(27,5 \%)$, seguindo-se "perspectivas de progressão na carreira” com 21,7\% e "salário/remuneração com $14,5 \%$.

É compreensível que a tentativa de mudança de emprego seja orientada segundo a realização profissional, ao mesmo tempo que se procura a possibilidade de conseguir empregos mais estáveis. No entanto, é curioso que o "salário/remuneração" não tenha maior peso nos resultados. Provavelmente, os mais preocupados com este factor são os recém-licenciados na procura da independência financeira. É neste sentido que Marques(9) diz que outros factores "não económicos" interferem nas decisões dos licenciados, que obedecem a motivações sociais, contemplando o emprego como um processo de concretização de aspirações e de realização profissional. Ao mesmo tempo, o conceito tradicional de carreira profissional começa a ser inconsistente, na medida em que muitos jovens não estão a trabalhar em empregos especificamente relacionados com a sua formação(1).

\section{Necessidades de contacto com instituição de formação inicial}

No que respeita à frequência de estudos pós-licenciatura, deparamos com uma grande percentagem de licenciados que não pretendem frequentar qualquer tipo de estudos posteriores, "pós-graduação" com $64 \%$ das respostas; "mestrado" com 26\%; e "doutoramento” com $70 \%$.

Ao contrário, o mestrado assume-se como a pós graduação que os alunos mais pretendem frequentar ou já frequentam, quer na universidade de formação inicial ou em outra.

$\mathrm{Na}$ investigação de Marques( ${ }^{(9)}$, em circunstâncias idênticas, a autora associa este investimento de formação, por parte dos recém-licenciados e finalistas, não só com a necessidade dos licenciados aperfeiçoarem e actualizarem conhecimentos adquiridos na universidade, mas também por terem receio de enfrentar o mercado de trabalho.
Em relação à formação extra na área do futebol, verificámos que praticamente todos os inquiridos frequentaram ou pretendem frequentar cursos de treinador, acções de formação, entre outros.

O processo de inserção na actividade profissional não é tarefa fácil, é repleto de obstáculos e estados de espírito que variam em função de se concretizarem (ou não) as expectativas $\operatorname{criadas}^{(4)}$. Deste modo, apercebemo-nos que alguns licenciados regressam à instituição formadora para procurar apoio, melhorando as suas qualificações e apetências na esperança de virem a ingressar no mercado de emprego.

Algumas das razões apontadas pelos licenciados, como necessidade de contacto com a instituição de formação inicial foram: "contacto com docentes" com a maioria da percentagem de respostas (32\%), seguido da "utilização da biblioteca" com 17\%. Em terceiro lugar está "exercício da sua actividade profissional", a par do "contacto com gabinete de futebol" com $16 \%$ do total das respostas.

\section{CONCLUSÕES}

Destacamos agora os aspectos mais importantes deste estudo:

Cerca de metade dos alunos inquiridos, ingressaram na licenciatura em educação física e desporto por gosto pessoal, associado às boas expectativas de saídas profissionais. Uma vez decididos pela licenciatura em causa, no $3^{\circ}$ ano da estrutura curricular, os licenciados escolheram o futebol como especialização, devido à possibilidade de vir a trabalhar no "mundo do futebol".

Os licenciados apresentaram uma opinião positiva em relação ao curso, bem como à opção de futebol. Neste último caso, manifestaram a necessidade de uma melhor divulgação no mercado de trabalho, um melhor contacto com a realidade exterior e melhorias no processo de supervisão dos centros de prática pedagógica, vulgarmente conhecidos por centros de treino.

Ao longo do seu percurso profissional, quase todos os licenciados exerceram ou exercem funções relacionadas com a sua especialização no futebol.

Relativamente ao seu emprego actual, a amostra inquirida está satisfeita com as funções que desempenha no seio das entidades empregadoras, apesar da sua insatisfação perante as hipóteses de melhorias salariais e as perspectivas de progressão na carreira. 
Os licenciados mais antigos não dão tanta ênfase ao emprego na área do futebol, uma vez que a sua solidez profissional há muito que passa pelos quadros do Ministério da Educação. Contudo, sentem-se bem a realizar funções adequadas à sua especialização, pondo em prática os conhecimentos relativos à opção de futebol.

Por outro lado, os recém-licenciados valorizam os empregos menos estáveis, em particular, no âmbito do futebol, pois sabe-se que a inserção profissional no ensino revela bastantes entraves. Assim, conciliam diversos empregos com o intuito de obter algumas contrapartidas, nomeadamente económicas. As principais denominações profissionais dos licenciados são, professor de educação física e treinador, nas áreas da licenciatura e da opção, respectivamente. Quanto às entidades empregadoras, a esmagadora maioria fica a cargo do Ministério da Educação e dos clubes, nas referidas áreas.

Nas profissões, o principal tipo de vínculo é o contrato a prazo e quanto às remunerações, a maioria dos licenciados que trabalham na escola afirmaram receber ente os 1000 e os 1500 euros. No caso dos que trabalham no futebol referiram valores inferiores a 250 euros e entre 250 e 500 euros. Notamos ainda que metade dos inquiridos conseguiram o $1^{\circ}$ emprego ainda antes do término da licenciatura.

No que concerne ao investimento em estudos posteriores constatamos que a maioria dos licenciados não pretende realizar qualquer tipo de formação póslicenciatura. Já no contexto do futebol, a realidade é bem diferente, visto que praticamente toda a amostra frequentou ou pretende frequentar cursos de treinador ou formações adjacentes. De qualquer modo, alguns licenciados mantêm o contacto com a instituição formadora, especialmente para o contacto com docentes.

A conclusão geral desta investigação prende-se com o facto global dos licenciados com opção de futebol estarem inseridos profissionalmente no mundo do futebol, exercendo cargos relacionados com a formação adquirida. Contudo, esta inserção profissional não se revela plenamente compensada, uma vez que necessitam de exercer funções noutros sectores do desporto para complemento do salário mensal.
NOTAS

${ }^{1}$ A declaração de Sorbonne, precede a declaração de Bolonha, com vista à harmonização do ensino superior, assinada em Paris, a 25 de Maio de 1998, pela Alemanha, França, Itália e Reino Unido.

http://www.aic.lv/rec/Eng/new_d_en/bologna/sorbon.html 2 A Declaração de Bolonha foi assinada em 19 de Junho de 1999, com o objectivo de introduzir um conjunto de reformas no ensino superior, permitindo uma maior harmonização, competitividade e atractividade para os estudantes europeus e de outros continentes, nomeadamente dos Estados Unidos da América e da Ásia.

http://ec.europa.eu/education/policies/educ/bologna/bologna_en.html

${ }^{3} \mathrm{Na}$ sequência do Desp. 1/ME/88, surge a Portaria $\mathrm{n}^{\circ} 464$ A/88, de 15 de Julho (suplemento ${ }^{\circ} 162$, I série do Diário da Republica) que fundamenta a criação legal da licenciatura.

\section{CORRESPONDÊNCIA}

\section{Victor Maçãs}

Universidade de Trás-os-Montes e Alto Douro

Departamento de Desporto

Quinta de Prados

Apartado 1013

5000-911 Vila Real

E-mail:vmacas@utad.pt 


\section{REFERÊNCIAS BIBLIOGRÁFICAS}

1. Almeida C (1993). Inserção na Vida Profissional dos Diplomados pela Escola Superior Agrária de Castelo Branco. Tese de Mestrado em Extensão e Desenvolvimento Rural. Universidade de Trás-os-Montes e Alto Douro, Vila Real. 162 pp.

2. CRUP (2004). Repensar o Ensino Superior: III. As funções da Universidade numa sociedade em mudança. Acedido em 19 de Junho de 2007 em: http://www.crup.pt/.

3. Cunha A (2002). A Opção de Futebol - (Quase) Uma Opção de Vida. Em: Maçãs, V. (ed.). Comunicações das I Jornadas Técnicas de Futebol. UTAD, Vila Real.

4. Frazão L (2005). Da Escola ao Mundo do Trabalho: Competências e Inserção Sócio-Profissional. Direcção Geral de Inovação e de Desenvolvimento Curricular. Lisboa.

5. Gonçalves A (2001). As Asas do Diploma: A inserção profissional dos Licenciados pela Universidade do Minho. Grupo de Missão para a Qualidade do Ensino/Aprendizagem. Braga.

6. IEFP (2005). Como procurar Emprego (Guia Prático). IEFP. Braga.

7. Maçãs V (2002). Os 10 anos da Opção de Futebol na UTAD. Em: Maçãs, V. (ed.). Comunicações das I Jornadas Técnicas de Futebol. UTAD, Vila Real.

8. Machado dos Santos S (2001). As responsabilidades da Universidade na formação de agentes para o desenvolvimento. Em: Gonçalves, A; Almeida, L. \& Outros (Eds.), Da Universidade para o Mundo do Trabalho: Desafios para um diálogo (pp. 13-39). Conselho Académico - Universidade do Minho, Braga.

9. Marques A (2002). Entre o Diploma e o Emprego: A Inserção Profissional de Jovens Engenheiros. Tese de Doutoramento em Sociologia. Universidade do Minho, Braga.
10. MCES (2003). Avaliação, revisão e consolidação da legislação do Ensino Superior - Documento de orientação. Acedido em 28 de Março de 2007, disponível em: http://www.crup.pt/Ensino_Superior.htm

11. Mirandela da Costa A (2002). A Universidade assumindo o Desporto. Em: Maçãs, V. (ed.). Comunicações das I Jornadas Técnicas de Futebol. UTAD, Vila Real.

12. Silva L (2005). Processo para o Seguimento do Percurso Profissional dos Graduados pela Universidade do Porto no Instituto de Recursos e Iniciativas Comuns da Universidade do Porto. Relatório de Estágio da Licenciatura em Ciência da Informação. Faculdade de Letras / Faculdade de Engenharia - Universidade do Porto, Porto.

13. UTAD (2008). Observatório do Percurso Profissional da Universidade de Trás-os-Montes e Alto Douro. UTAD Vila Real

14. Valadas S, Gonçalves F, Outros (2006). Percursos de empregabilidade dos licenciados: Perspectivas europeias e nacional. Observatório Permanente para a Qualidade de Ensino Universidade do Algarve. Acedido em 22 de Março de 2007, disponível em:

http://www.scielo.oces.mctes.pt/pdf/aps/v24n1/v24n1a10 .pdf.

15. Veiga Simão J, Machado dos Santos S, Costa A (2004). Resultados do estudo efectuado pelo grupo de trabalho para a reorganização da rede do Ensino Superior. Bolonha: Agenda para a excelência. Acedido a 12 de Maio de 2007, em: http://www.portugal.gov.pt/Portal/PT/Governos/Governos _Constitucionais/GC16/Ministerios/MCIES/Comunicacao /Publicacoes/20041011_MCIES_Pub_Bolonha.

16. Vernières M (1997). L'insertion professionnelle. Analyses et Débats. Paris, Ed. Economic. 